\title{
Pre-emergence Liverwort Control in Nursery Containers
}

\author{
Adam Newby ${ }^{1}$, James E. Altland ${ }^{2,5}$, Charles H. Gilliam ${ }^{3}$, \\ and Glenn Wehtje ${ }^{4}$
}

AdDitional INDEX wORDs. Marchantia polymorpha, hepatic, weed control

Summary. Experiments were conducted in Auburn, AL, and Aurora, OR, to evaluate herbicides for pre-emergence liverwort (Marchantia polymorpha) control. Granular pre-emergence herbicide efficacy varied by location and product. Summarizing across all experiments, flumioxazin and oxadiazon provided the most effective control in Alabama, whereas flumioxazin and oxyfluorfen + oryzalin provided the most effective control in Oregon. Sprayed quinoclamine provided pre-emergence liverwort control, but efficacy and duration of control were reduced compared with granular herbicides.

$\mathrm{L}$ iverwort is a common weed in nursery containers throughout the United States. It is a primitive spore-bearing plant in the class Hepaticae. Liverwort thrives in conditions with high light (O'Hanlon, 1926), low ultraviolet radiation (True et al., 2006), high humidity or soil moisture (Svenson, 1998), and high fertility. These conditions are typical of many propagation and container production environments.

Ross and Puritch (1981) documented the introduction and spread of liverwort, mosses, and algae in greenhouses. They (Ross and Puritch, 1981) reported that liverwort was not introduced into greenhouses from water supplies or peatmoss, but instead was introduced from preexisting colonies within the greenhouse, or airborne spores infiltrating the greenhouse through the ventilation system. Ross and Puritch (1981) also attributed the spread of the most abundant cryptogams in greenhouses, liverwort and silvery thread moss (Bryum argenteum), to their

Funded in part by a grant from The Horticultural Research Institute, 1000 Vermont Ave., N.W. Suite, Washington, DC 20005

${ }^{1}$ Graduate Research Assistant, Department of Horticulture, Auburn University, 101 Funchess Hall, AL 36849

${ }^{2}$ Assistant Professor, Oregon State University, North Willamette Research and Extension Center, 15210 NE Miley Road, Aurora, OR 97002

${ }^{3}$ Professor, Department of Horticulture, Auburn University, 101 Funchess Hall, AL 36849

${ }^{4}$ Professor, Department of Agronomy, Auburn University, 201 Funchess Hall, AL 36849

${ }^{5}$ Corresponding author. E-mail: james.altland@ oregonstate.edu. ability to propagate both asexually and sexually. Liverwort spread asexually via splashing of gemmae or sexually via dissemination of airborne spores. Gemmae cups are circular projections that cover the thallus surface. Within gemmae cups are asexually produced diaspores called gemmae. Gemmae can be splashed up to $1.6 \mathrm{~m}$ from the mother plant when hit with rain or irrigation (England and Jeger, 2006).

Liverwort is a unisexual plantthat is, each plant is either male or female. Female reproductive stalks, called archegoniophores, only occur on female plants and are deeply lobed with finger-like projections. Male reproductive stalks, called antheridiophores, occur only on male plants and appear more disk shaped and flat on top. In nurseries where liverwort has been a problem, we have observed both sexes to be present in most containers (personal observation). Each archegoniophore contains approximately seven million viable spores (O'Hanlon, 1926), and there can be as many as 50 to 75 archegoniophores in a typical l-gal container (personal observation). Spores are viable for $\approx 1$ year after release from the mother plant (O'Hanlon, 1926).

Limited research has addressed pre-emergence liverwort control. Preventive liverwort control is preferable to hand removal. Rhizoids that grow along the ventral surface of the thallus make hand removal difficult. It is often necessary to remove the surface $\mathrm{l}$-inch layer of the substrate to remove liverwort from containers (personal observation). This necessitates adding new substrate to fill the pot, further increasing costs of hand removal. Svenson et al. (1997) listed products that provide pre-emergence liverwort control in summary form (no data). They (Svenson et al., 1997) described pre-emergence control with oxyfluorfen, oryzalin, isoxaben, and oxadiazon as fair, fair to good, fair to good, and fair to very good respectively. Svenson (1998) later documented slightly better preemergence liverwort control with oxadiazon compared with oryzalin in both low- and high-frequency irrigation settings. Wilson and Hughes (1985) reported that oryzalin applied at 9-week intervals provided 99\% liverwort control compared with 76\% control with oxadiazon applied at a similar frequency. Fausey (2003) reported that flumioxazin sprayed as a $50 \%$ water dispersible granule provided $100 \%$ pre-emergence liverwort control $35 \mathrm{~d}$ after treatment (DAT) and $74 \%$ pre-emergence control 60 DAT. In a separate experiment, the same product provided $98 \%$ preemergence control 60 DAT, whereas flumioxazin applied as a $0.17 \%$ granular provided $95 \%$ pre-emergence control 60 DAT (Fausey, 2003). However, none of the aforementioned herbicides are labeled for use in enclosed structures where liverwort pressure is greatest.

Quinoclamine (Gentry, 25\% wettable powder; Chemtura Corp., Middlebury, CT) is labeled for liverwort control in nursery crops in parts

\begin{tabular}{llll}
\hline $\begin{array}{l}\text { Units } \\
\begin{array}{l}\text { To convert U.S. to SI, } \\
\text { multiply by }\end{array}\end{array}$ & U.S. unit & SI unit & $\begin{array}{l}\text { To convert SI to U.S., } \\
\text { multiply by }\end{array}$ \\
\hline 0.3048 & $\mathrm{ft}$ & $\mathrm{m}$ & 3.2808 \\
3.7854 & $\mathrm{gal}$ & $\mathrm{L}$ & 0.2642 \\
25.4000 & inch $(\mathrm{es})$ & $\mathrm{mm}$ & 0.0394 \\
1.1209 & $\mathrm{lb} / \mathrm{acre}$ & $\mathrm{kg} \cdot \mathrm{ha}^{-1}$ & 0.8922 \\
0.5933 & $\mathrm{lb} / \mathrm{yard}^{3}$ & $\mathrm{~kg} \cdot \mathrm{m}^{-3}$ & 1.6856 \\
6.8948 & $\mathrm{psi}$ & $\mathrm{kPa}$ & 0.1450 \\
0.1019 & $\mathrm{qt} / 100 \mathrm{ft}^{2}$ & $\mathrm{~L} \cdot \mathrm{m}^{-2}$ & 9.8170
\end{tabular}


of Europe. The mode of action for this compound is light-induced radical formation, which leads to deterioration of the photosynthetic system and rapid pigment bleaching (Chemtura Corp., unpublished). The product is marketed as Mogeton in other parts of the world, and has been researched in the United States under the same name. Chemtura Corp. is currently seeking a section 3 registration for Gentry in nursery and greenhouse crops in the United States (submitted to the U.S. Environmental Protection Agency on 26 Feb. 2006). Extensive evaluation through the IR-4 program has demonstrated that a broad spectrum of nursery crops are tolerant of applications made over the top in outdoor or greenhouse production sites (Vea and Palmer, 2006). Research has demonstrated effective postemergence liverwort control with quinoclamine, with reduced recolonization of treated containers after application to existing colonies. Newby et al. (2005) documented reduced liverwort recolonization with increasing quinoclamine rates despite similar levels of postemergence control, indicating some residual activity. Svenson et al. (1997) stated that quinoclamine is best used for pre-emergence control, but offered no justification. Wilson and Hughes (1985) reported that oryzalin + quinoclamine applied at 9 -week intervals provided $99 \%$ to $100 \%$ liverwort control over a 2 -year study; however, in the same study oryzalin applied alone provided 99\% control, so it is not clear whether quinoclamine provided any additional control. Senesac (2005) reported a slight, but significant, level of residual control on new liverwort infestation over a 5 -week period when quinoclamine was applied to initially weed-free containers.

There is increasing liverwort pressure in nurseries throughout the United States, and a lack of information providing control recommendations with products currently labeled. This, coupled with the pending registration of quinoclamine in the United States, highlights a need for research on preventive liverwort control. The objective of this study was to evaluate granular herbicides and spray-applied quinoclamine for pre-emergence liverwort control in container crops.

\section{Materials and methods}

General information. Seven experiments were conducted in either Auburn, AL, or in Aurora, OR. Experiments conducted in Alabama were in 1-gal containers filled with aged 6 pine bark (Pinus taeda) : 1 sand $(\mathrm{v} / \mathrm{v})$ substrate amended with 14 lb/yard ${ }^{3} 18 \mathrm{~N}-2.6 \mathrm{P}-10 \mathrm{~K}$ (18-612; Pursell Technologies, Sylacauga, AL), $5 \mathrm{lb} /$ yard $^{3}$ dolomitic lime, and $1.5 \mathrm{lb} /$ yard $^{3}$ Micromax (Scotts Co., Marysville, $\mathrm{OH})$. Experiments in Oregon were conducted with 1-gal containers filled with aged Douglas Fir (Psuedotsuga menziesii) bark amended $16 \mathrm{lb} / \mathrm{yard}^{3} 18 \mathrm{~N}-2.6 \mathrm{P}-$ $10 \mathrm{~K}$ (Scotts Co.) and $1.5 \mathrm{lb} /$ yard $^{3}$ Micromax micronutrients (Scotts Co.). In Alabama, quinoclamine was applied in a spray chamber equipped with a single 8005 flat fan nozzle (Spraying Systems Co., Wheaton, IL) pressurized to $35 \mathrm{psi}$ and calibrated to deliver $1 \mathrm{qt} / 100 \mathrm{ft}^{2}$. In Oregon, quinoclamine was applied with a $\mathrm{CO}_{2}$-pressurized backpack sprayer at the same spray volume and pressure, but using a three-nozzle boom and 8008 flat fan nozzles (Spraying Systems Co.). Granular herbicides at both locations were applied with a handheld shaker. Data within each experiment were subjected to repeated-measures analysis of variance, and means were separated with Duncan's multiple range test $(\alpha=0.05)$. Contrast analyses were used when appropriate.

Expt. 1: Auburn, AL. Ten granular herbicides were applied at their labeled rate on 6 July 2004. Treatments included flumioxazin (BroadStar, 0.25\% granular; Valent U.S.A. Corp., Walnut Creek, CA) at $0.35 \mathrm{lb} /$ acre a.i., oxadiazon + pendimethalin (Kansel+, 3.25\% granular; The Scotts Co.) at $3 \mathrm{lb} /$ acre a.i., oxyfluorfen + pendimethalin $(\mathrm{OH} 2$, $3 \%$ granular; The Scotts Co.) at $3 \mathrm{lb} /$ acre a.i., pendimethalin (Pendulum, 2\% granular; BASF Corp., Florham Park, NJ) at $4 \mathrm{lb} /$ acre a.i., oxyfluorfen + oxadiazon (Regal O-O, 3\% granular; Regal Chemical Co., Alpharetta, GA) at $3 \mathrm{lb} /$ acre a.i., prodiamine (RegalKade, 0.5\% granular; Regal Chemical Co.) at $1 \mathrm{lb} /$ acre a.i., oxadiazon + prodiamine (RegalStar, 1.2\% granular; Regal Chemical Co.) at $2.4 \mathrm{lb} /$ acre a.i., oxadiazon (Ronstar, $2 \%$ granular; Aventis, Montvale, NJ) at
$4 \mathrm{lb} /$ acre a.i., oxyfluorfen + oryzalin (Rout, 3\% granular; The Scotts Co.) at $3 \mathrm{lb} /$ acre a.i., and isoxaben + trifluralin (Snapshot, 2.5\% granular; Dow AgroSciences, Indianapolis) at $5 \mathrm{lb} /$ acre a.i. All treatments, including a nontreated control, were applied to four replications with four containers per replication. After application, all containers from a common replication were placed around a l-gal container infested with mature liverwort to provide a constant source of inoculation from splashing gemmae and airborne spores. A completely randomized design was used. The experiment was conducted outdoors under $47 \%$ shade. Overhead irrigation was applied at one-quarter inch/d split into two cycles. Percent liverwort control, measured as percent of the substrate surface not covered with liverwort, was recorded 6,11 , and 17 weeks after treatment (WAT).

A second repetition of this experiment was initiated on 18 Oct. 2005 with a reduced number of herbicide treatments including oxyfluorfen + oryzalin, oxyfluorfen + oxadiazon, flumioxazin, oxadiazon, and a nontreated control, all applied at the same rates as listed earlier. Liverwort control was recorded 12, 18, and 21 WAT.

Expt. 1: Aurora, OR. This experiment was conducted concomitantly with the first repetition of Expt. 1 in Auburn, and was conducted similarly except that oxadiazon + napropamide (Pre Pair, 6\% granular; UAP Professional Products, Greeley, CO) also was applied at $9 \mathrm{lb} /$ acre a.i. The experiment was not repeated in Aurora.

Expt. 2: Auburn, AL. Treatments were applied to containers on 23 Sept. 2004. Quinoclamine was applied at $1.7,3.4$, and $6.8 \mathrm{lb} /$ acre a.i. Granular herbicide treatments were flumioxazin, oxadiazon, and oxyfluorfen + oryzalin at the same rates used in Expt. 1. Each treatment consisted of four replications with four containers per replication. Containers were randomized and arranged similarly to Expt. 1. Overhead irrigation was applied at one-quarter inch $/ \mathrm{d}$ split into three cycles. Percent liverwort control was recorded 6,10 , and 18 WAT.

A second repetition of this experiment was initiated on 21 Oct. 2005. Liverwort control was recorded 12,18 , and 21 WAT. 
ExPT. 2: Aurora, OR. This experiment was conducted similarly to that described for Alabama. Treatments were applied 28 Sept. 2004 and data were collected 9, 14, and 18 WAT. A second repetition of the experiment was initiated on 18 Apr. 2005. The lowest rates of quinoclamine and oxyfluorfen + oryzalin were dropped from the second repetition. Liverwort control was recorded 4, 6, and 10 WAT.

\section{Results and discussion}

Expt. 1: Auburn, AL. All herbicides provided at least $82 \%$ liverwort control 6 WAT (Table 1). Only flumioxazin and oxadiazon provided $100 \%$ control, although five other treatments provided statistically similar control. By 11 WAT, liverwort control was still good $(>80 \%)$ in containers treated with flumioxazin, oxyfluorfen + oxadiazon, and oxadiazon. Ten to 12 weeks of control is generally the assumed maximum longevity of efficacy for pre-emergence herbicides in container crops. Isoxaben + trifluralin, prodiamine, and pendimethalin did not improve control above what was observed in nontreated containers. By 17 WAT, only flumioxazin provided effective $(>80 \%)$ control. Oxyfluorfen + oxadiazon and oxadiazon alone reduced liverwort growth compared with nontreated controls, but provided only $45 \%$ and $68 \%$ control respectively. No other herbicide reduced liverwort growth below that observed in nontreated containers.

In a second repetition of the study in Auburn, liverwort was slower to colonize and infest containers (Table 1). Other research has documented that liverwort vigor responds to seasonal temperature and ultraviolet light levels (Newby et al., 2006). By 18 WAT, most products still provided effective control. However, by 21 WAT, only flumioxazin and oxadiazon remained effective. Across both repetitions of the experiment, oxadiazon outperformed oxyfluorfen + oryzalin, which is contrary to other research (Wilson and Hughes, 1985) that reported better control with oryzalin. One explanation for this is that the combination product of oxyfluorfen + oryzalin only provided $1 \mathrm{lb} /$ acre a.i. oryzalin, which is only $25 \%$ of the oryzalin rate used by Wilson and Hughes (1985).

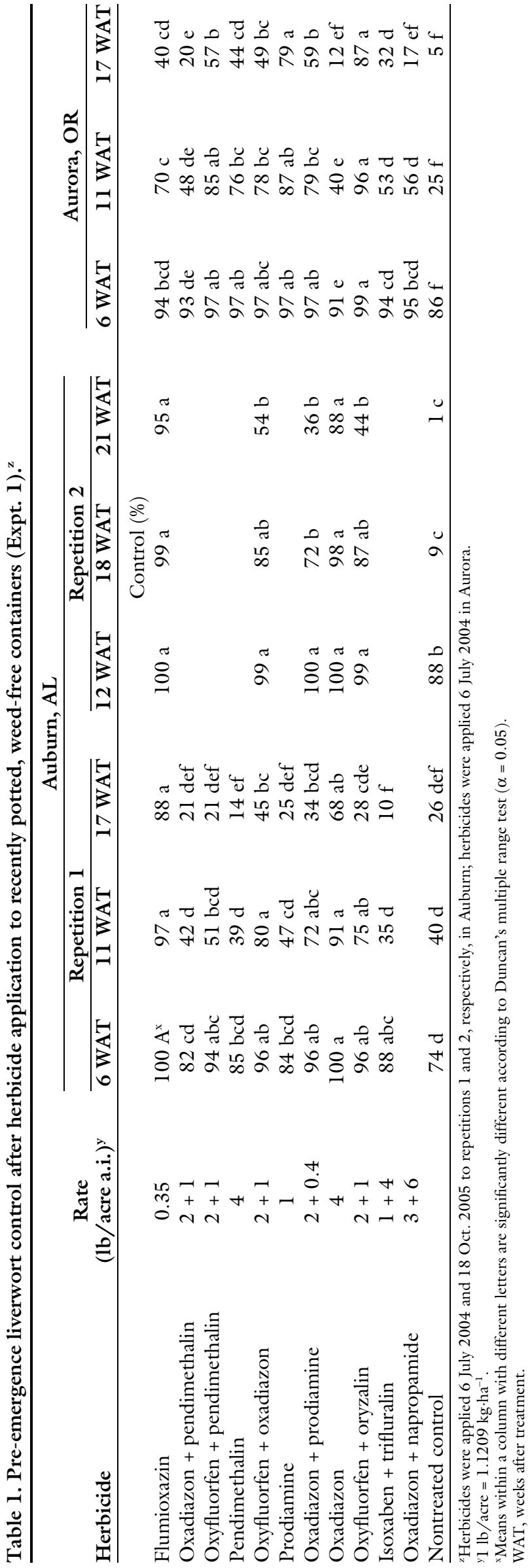


EXPT. 1: Aurora, OR. All products provided effective control through 6 WAT (Table 1). By 11 WAT, oxyfluorfen + oryzalin, prodiamine, and oxyfluorfen + pendimethalin provided the most effective control $(>80 \%)$, although three other products provided statistically similar control. By 17 WAT, oxyfluorfen + oryzalin and prodiamine provided the most effective control in Oregon, although neither compound provided effective control this late in Alabama. In addition, although flumioxazin and oxadiazon were the most effective in Alabama, they were among the least effective in Oregon. Environmental conditions, container substrates, and irrigation systems differed between the two sites. Although environmental and cultural practices might be used to explain differences in efficacy across all treatments, they do not explain the seemingly opposite responses of flumioxazin, oxadiazon, prodiamine, and oxyfluorfen + oryzalin at the two locations.

Expt. 2: Auburn, AL. All products provided nearly complete control through 6 WAT (Table 2). By 10 WAT, the granular pre-emergence herbicides still provided complete control. Control with quinoclamine 10 WAT was slightly reduced with all rates, but still greater than nontreated containers (contrast analyses, Table 2). By 18 WAT, control was still acceptable with granular pre-emergence herbicides. Quinoclamine provided little or no control by this time.

Liverwort was generally slower to colonize in the second repetition of this study compared with the first (not compared statistically). By 12 WAT, control from quinoclamine had already begun to decline to less than that provided by granular preemergence herbicides, although it was slightly better than nontreated controls. Similar to the first repetition, liverwort control with quinoclamine was completely lost 18 WAT, but control provided by granular herbicides was still effective. By 21 WAT, flumioxazin and oxyfluorfen + oryzalin still provided effective control $(>80 \%)$ whereas oxadiazon control declined to $68 \%$. Similar to Expt. 1, flumioxazin and oxadiazon provided effective control through 18 weeks. Oxyfluorfen + oryzalin, which provided poor liverwort control at 18 weeks in both repetitions of Expt. 1

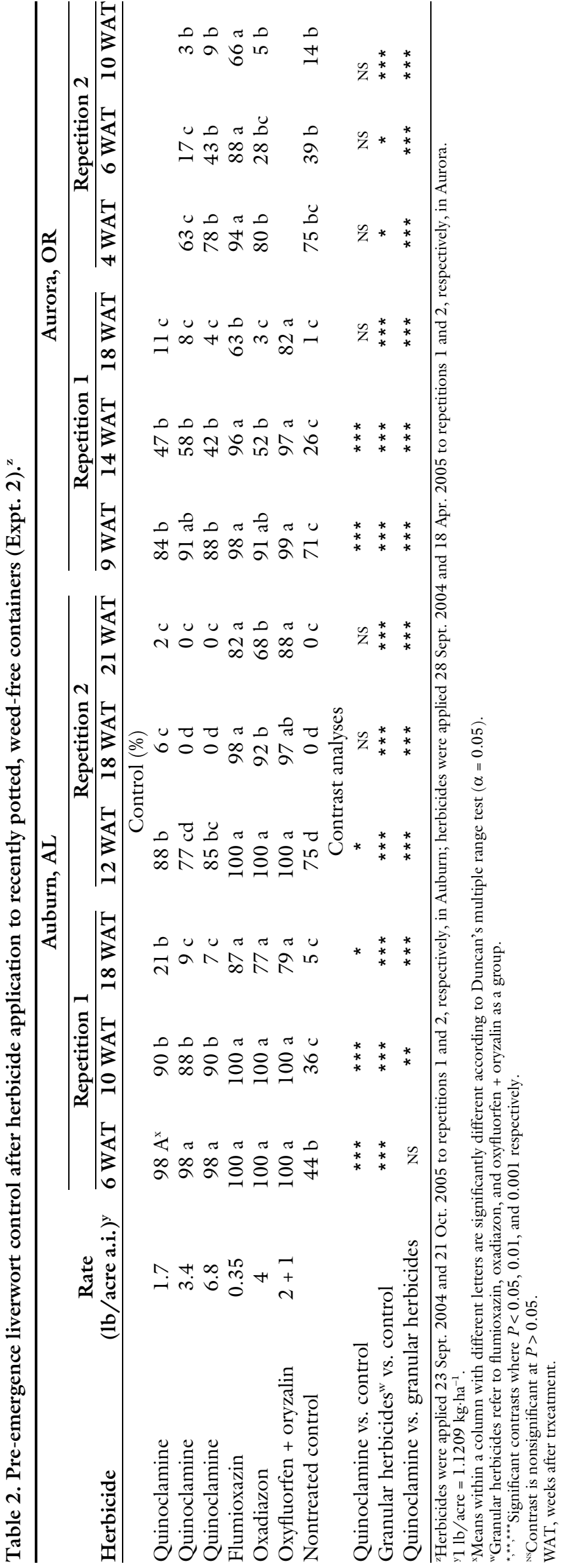


in Alabama, was more effective in this experiment.

Expt. 2: Aurora, OR. At 9 WAT, all herbicides provided some level of control, with granular preemergence herbicides providing better control $(96 \%)$ compared with quinoclamine $(88 \%)$. By 14 WAT, liverwort control from quinoclamine averaged just $49 \%$ across three rates whereas flumioxazin and oxyfluorfen + oryzalin continued to provide excellent control $(\geq 96 \%)$. By 18 WAT, quinoclamine and oxadiazon provided no control, whereas oxyfluorfen + oryzalin provided the most control, with slightly reduced control from flumioxazin. These results concur with Expt. 1 in Oregon, where oxyfluorfen + oryzalin provided effective control and oxadiazon provided poor control.

Repetition 2 of this Expt. in Oregon provided similar results. Liverwort growth in containers treated with quinoclamine and oxadiazon was similar to nontreated controls. Flumioxazin provided the most effective control, although it was reduced to $66 \%$ in 10 weeks. This experiment was initiated in April when temperatures and light levels are ideal for liverwort growth in Oregon. Liverwort control across treatments may have been reduced compared with other similar experiments because of greater liverwort vigor (experiments were not compared statistically).

Across both regions and all experimental repetitions, no herbicide treatment consistently provided effective control. In Alabama, flumioxazin and oxadiazon were most effective, whereas oxyfluorfen + oryzalin was not consistently effective. In Oregon, oxyfluorfen + oryzalin was the most consistent and effective treatment.

Discrepancy in efficacy between the two regions might be explained by differences in liverwort populations. Although it is possible that Alabama and Oregon have similar populations introduced from common nursery crops, it is also possible that populations are distinct. Underwood (1895) described liverwort $(M$. polymorpha) as almost universally distributed throughout the United States and the world. This description of the plants' range predates interstate nursery trade. Thus, locally adapted liverwort populations may dominate containers in both Alabama and Oregon, and respond differently to herbicides. Liverwort populations between Oregon and Alabama are not isolated by oceans or other natural barriers, and thus interstate nursery trade might preclude some from considering this explanation. However, Oregon exports only 3\% of its crop annually to the Gulf States region (including Oklahoma, Texas, Arkansas, Louisiana, Tennessee, Mississippi, and Alabama) (Mertz et al., 2005). Because of limited trade between Alabama and Oregon, it seems plausible that genetically different populations of liverwort could predominate in the two regions.

Quinoclamine provided some pre-emergence liverwort control, although for a shorter period of time than the most effective granular preemergence herbicides. Senesac (2005) also reported slight residual activity by quinoclamine, but did not compare it with other granular preemergence herbicides. Similarly, Newby et al. (2005) reported reduced liverwort recolonization after making postemergence applications of quinoclamine. Considering the effectiveness of quinoclamine in postemergence liverwort control as documented previously (Newby et al., 2006), we conclude that quinoclamine be viewed primarily as a postemergence tool for controlling small liverwort infestations. The benefit of some residual activity will be realized with periodic applications. Upon registration, quinoclamine will be labeled for use inside greenhouses and other enclosed structures where other residual preemergence herbicides are prohibited (not labeled).

\section{Literature cited}

England, J. and M. Jeger. 2006. Liverwort gemmae dispersal: The effect of overhead irrigation and its influence on gemmae production. Proc. Northeast Weed Sci. Soc. 60:24 (abstr.).

Fausey, J.C. 2003. Controlling liverwort and moss now and in the future. HortTechnology 13:35-38.
Mertz, C.A., B. Eklund, K. Hoddick, C. Bennett, E. Stebbins, and M. Viste. 2005. Oregon nursery and greenhouse survey. 16 Oct. 2006. <www.nass.usda.gov/ Statistics_by_State/Oregon/Publications/ Horticulture/nursery2006.pdf>.

Newby, A., J. Altland, C. Gilliam, and G. Wehtje. 2006. Postemergence liverwort control in container-grown nursery crops. J. Environ. Hort. 24:230-236.

Newby, A., J. Altland, C. Gilliam, G. Wehtje, and D. Fare. 2005. Controlling liverwort (Marchantia polymorpha) infestations. Proc. Southern Nursery Assn. Res. Conf. 50:468-471.

O'Hanlon, M.E. 1926. Germination of spores and early stages in development of gametophyte of Marchantia polymorpha. Bot. Gaz. 82:215-222.

Ross, R.L.M. and G.S. Puritch. 1981. Identification, abundance, and origin of moss, liverwort, and algal contaminants in greenhouses of containerized forest nurseries. Can. J. For. Res. 11:356360 .

Senesac, A.F. 2005. Evaluation of Mogeton for liverwort control in container nurseries. Proc. Weed Sci. Soc. Amer. 45:32 (abstr.).

Svenson, S.E. 1998. Suppression of liverwort growth in containers using irrigation, mulches, fertilizers and herbicides. Proc Southern Nursery Assn. Res. Conf. 43:396-398.

Svenson, S.E., B. Smith, and B. Briggs. 1997. Controlling liverworts and moss in nursery production. Comb. Proc. Intl. Plant Prop. Soc. 47:414-422.

True, N., R. Aanenson, and L. Fuselier. 2006. Effects of ultraviolet (UV) radiation on asexual propagules of Marchantia polymorpha. Proc. Bot. Soc. Amer. Abstr. 346. 1 June 2007. <www.2006. botanyconference.org/engine/search/ index.php? func $=$ detail \&aid $=346>$.

Underwood, L.M. 1895. Notes on our Hepaticeae. III. The distribution of the North American Marchantiaceae. Bot. Gaz. 20:59-71.

Vea, E. and C. Palmer. 2006. Quinoclamine crop safety. 14 Feb. 2006. http://ir4. rutgers.edu/ornamental/SummaryReports/ QuinoclamineDataSummary2005.pdf .

Wilson, D. and A. Hughes. 1985. Evaluation of oryzalin and Mogeton for weed control in field and container grown hardy nursery stock. Br. Crop Protection Conf. Weeds 3:1095-1102. 